\title{
Total phenolic contents, radical scavenging and cyclic voltammetry of seaweeds from Brittany
}

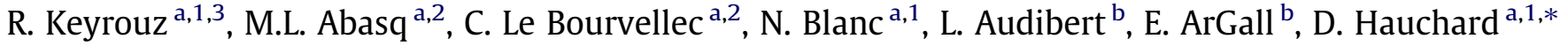 \\ a Sciences Chimiques Rennes, UMR CNRS 6226, Ecole Nationale Supérieure de Chimie de Rennes, Université de Rennes 1, Avenue du Général Leclerc, CS 50837, \\ 35708 Rennes Cedex 7, France

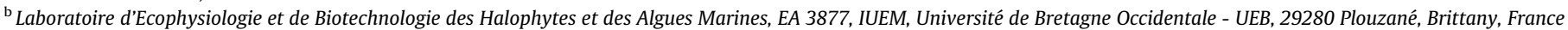

\begin{abstract}
A B S T R A C T
The role of polyphenols as antioxidants in our daily nutrition has been extensively investigated, but information on composition of tannins from marine sources on nutrient utilisation is limited. This study will be focused on the determination of the polyphenol quantities in brown seaweeds from Brittany coast in France; the extracts were delivered from algae centre for valorisation (CEVA), and the fidelity of the method was examined intraday and interlaboratories. The seaweed's extracts are divided into three categories: Fucus Vesiculosus, Ascophyllum nodosum and Fucus Serratus. Consequently, the total polyphenol contents (TPC) of these extracts will be measured using Folin-Glombitza spectrophotometric method. Thereafter, the antioxidant properties of these polyphenols were determined using the 2,2-diphenyl1-picrylhydrazyl (DPPH) radical scavenging. All polyphenols extracted were tested using cyclic voltammetry (CV) in aprotic media. The CV is realised to compare the results from spectroscopic method and to electrochemically characterise the seaweed's polyphenols.
\end{abstract}

Keywords:

Antioxidant

Seaweed extracts

Folin-Glombitza method

DPPH

Cyclic voltammetry

\section{Introduction}

Antioxidants are of interest to the food industry, because they prevent rancidity and are as well of interest to biologists and clinicians, because they may help to protect the human body against damage by reactive oxygen species (ROS) (Halliwell, 1999; Prior \& Cao, 1999). An ample variety of reactive oxygen species (ROS) such as the superoxide anion-radical $\left(\mathrm{O}_{2}^{--}\right)$, hydroxyl radicals (HO) and other non-radicals oxygen derivatives, e.g., hydrogen peroxide $\left(\mathrm{H}_{2} \mathrm{O}_{2}\right)$ and singlet oxygen $\left(1 \mathrm{O}^{2}\right)$ are constantly generated in vivo, as an integral part of metabolism, as part of controlled inflammatory reactions, and as result of exposure to environmental factors (Halliwell, 1996). A pathological enlarge of ROS generation has been recognised in over 100 animal and human diseases including cardiovascular disease, cancer, diabetes mellitus, renal disease and dialysis, lung and inflammatory diseases (Moore, Calder, Miller, \& Rice-Evans, 1994; Pinzani et al., 1998). ROS circulate freely in the body with access to all tissues and organs. They cause tissue damage by a variety of different mechanisms including, damage to proteins and DNA, lipid peroxidation, oxidation of

\footnotetext{
* Corresponding author. Tel.: +332 23 238044; fax: +332 23238199.

E-mail address: didier.hauchard@ensc-rennes.fr (D. Hauchard).

1 MaCSE group

2 PNSCM group

${ }^{3}$ Present address: Université Libanaise, Faculté des Sciences II, Département de Chimie, B.P. 26110217, Fanar, Liban
}

important enzymes, and stimulation of pro-inflammatory cytokine release by monocytes and macrophages (Kowaltowski \& Vercesi, 1999; Simic \& Bergtold, 1991).

Moreover, in recent years, numerous research studies have associated the consumption of foods rich in polyphenols with the prevention of cardiovascular diseases related to ageing, thanks to their antioxidant properties (Pratt, 1992; Rice-Evans \& Miller, 1998). Many active ingredients, such as vitamins, chlorophyll, dietary fibres and polyphenol are distributed in vegetables, fruit, edible seaweeds and teas. They inhibit mutation and scavenge active oxygen and free radicals. Polyphenols, including more than 4000 related compounds, were found to have anti-oxidative and antimutagenic activities, and cholesterol-lowering effects (Cao, Sofic, \& Prior, 1996). Interest in natural sources of antioxidant molecules in the food and beverage and cosmetic industries has resulted in a large body of research in recent years characterising the mechanisms of action of well known lipid- and water-soluble antioxidants such as the tocopherols and ascorbic acid, respectively, as well as antioxidants. Fruits, vegetables and oilseeds are increasingly recognised as sources not only of vitamins, minerals, soluble and insoluble dietary fibre, but also phenolic compounds including phenolic acids, flavonoids, isoflavones and lignans (He \& Shahidi, 1997).

Hence, the agroalimentary activity of the Brittany in France is largely dominated by the production and the valorisation of agricultural and marine products origin. Seaweed products as raw materials, which may undergo national benefit, represent within 
this framework an important potential in the region. The interest which one currently carries to the algae, especially brown seaweeds, rests mainly on their nutritional quality. The algae, in more of their high content in fibres, vitamins and minerals, contain important content of polyphenols. These compounds are known today for their antioxidant capacities. The main question in this phase is how to identify seaweed's polyphenols and how can we determine successfully their antioxidant capacity?

Although the considerable importance of antioxidants, there is not a unique method or protocol for determination of antioxidant capacity (ORAC, FRAP, TEAC. . ) (Benzie \& Strain, 1996; Cao, Alessio, \& Culter, 1993; Guo et al., 2003; Re et al., 1999; Roginsky \& Lissi, 2005; Van Den Berg, Haenen, Van Den Berg, \& Bast, 1999). Therefore, results obtained from all these methods are not constantly compatible and materials used for these analyses are costly (AAPH, ABTS, DPPH...). That is why we thought to manage a new competent system, which can offer systematically results and can economise expensive raw materials. Moreover, we developed a new technique applied to qualitative determination of vegetables ingredients "seaweed polyphenols" using less complicated methods, compared with chromatographic techniques using complicated apparatus.

A highly attractive, convenient and especially sensitive voltammetry approach for the study of antioxidant properties, quality control and determination of their activities is suggested in this work, where antioxidants are substances, which interrupt radical-chain oxidation in organic and inorganic molecules. Our method consists in using electrochemical techniques, cyclic voltammetry (CV), for quality control of seaweed and for determination of their antioxidant capacities. Due to these electrochemical techniques, we have been able to characterise a number of new antioxidants species and to compare the antioxidant activity of seaweed's extracts, apple's extracts and commercial polyphenols. Electrochemical methods appear as simple methods giving good estimations of the global amount of polyphenols in vegetables and plants. Furthermore, these techniques have been capable to give the global amount of different types of polyphenols in the same time and to characterise new compounds containing polyphenols which could play important role in food and pharmaceutical industry.

Thus, in the present paper, the first part is focused on spectroscopic techniques used to study brown seaweed extracts, extracted from Brittany cost (France), in purpose to determine their total polyphenol contents (TPC). The seaweed's extracts are divided into three types: Fucus vesiculosus (FV), Ascophyllum nodosum (AN) and Fucus serratus (FS). It should be noted that in the spectroscopic section we used Folin-Glombitza method to determine their polyphenols consistence. In the second part of this study we were interested to study their antioxidant capacity using the 2,2diphenyl-1-picrylhydrazyl DPPH as a scavenging radical reagent. Also, and for the main reason in the third part, these extract's were tested electrochemically, using cyclic voltammetry, to determine their electrochemically response. This technique can provide us the composition of each extracts, qualitatively, and can give us the global amount of polyphenols in each extract. Moreover, some commercial polyphenols (catechin, quercitin, rutin...) were also electrochemically studied to determine their oxidation waves.

\section{Experimental}

\subsection{Apparatus and reagents}

All spectroscopic studies were performed on a UV-Vis spectrophotometer schimadzu PTI (PTI-814 PDS, MD 5020, LPS 220B) and all the solutions were tested in plastic cells. Cyclic voltammetry experiments were preformed on a dual potentio-galvanostat Pgstat100 and an Applied Princeton Research EG\&G 263A potenstiostat. All measurements were carried out on a three-electrode cell $(10 \mathrm{ml})$. A glassy carbon disk working electrode (diameter $2 \mathrm{~mm}$ ), a platinum wire counter electrode and a reference electrode $\mathrm{Ag} / \mathrm{AgCl}$ in $\mathrm{EtOH}$ saturated by $\mathrm{LiCl}$, were used for all electrochemical experiments. The reference electrode was separated from the solution by a salt bridge containing $0.5 \mathrm{M} \mathrm{Bu}_{4} \mathrm{NPF}_{6}$ in DMF. The glassy carbon were polished to a mirror finish using a Struers Dap-7-polishing kit and $0.05 \mu \mathrm{m}$ alumina slurry; following this, they were rinsed with twice distilled water and acetone and dried in air.

The CV was carried in a one compartment cell-containing $0.1 \mathrm{M}$ tetrabutylammonium hexafluorophosphate $\left(\mathrm{Bu}_{4} \mathrm{NPF}_{6}\right)$. The $\mathrm{Bu}_{4} \mathrm{NPF}_{6}$ of electrochemical grade was purchased from Fluka Chemie (Buchs, Suisse). The $N, N$-dimethylformamide extra dry was purchased from Acros Organics and stocked under argon with molecular sieves $3 \mathrm{~A}^{\circ}$ (Geel, Belgium).

Phloroglucinol, (+)-catechin, (-)-epicatechin, phloridzin, quercetin, rutin, chlorogenic acid, $p$-coumaric acid, caffeic acid, $t$-cinnamic acid and cinnamic acid were purchased from Sigma Chemical Co. (St Louis, MO, USA). Ferulic acid was purchased from Merck (Munich, Germany). Ascorbic acid was purchased from Carlo Erba Reagenti (Rodane, MI, Italy). Trolox (( \pm )-6-hydroxy-2,5,7,8tetramethylchromane-2-carboxylic acid) was purchased from Acros Organics (Geel, Belgium). Apple extracts, supplied by Diana Naturals - Seaweed extracts, were supplied by CEVA (Centre d'Etude et de Valorisation des Algues, Pleubian, France).

\subsection{Seaweed sampling}

The seaweeds used for this study were freshly collected from the Côte D'armor coastline of Brittany, Republic of France. The seaweed samples collected were all brown seaweeds and were divided into three species: Fucus vesiculosus (Fucaceae, Fucus, F. vesiculosus), Ascophyllum nodosum (Fucaceae, Ascophyllum, A. nodosum) and Fucus serratus (Fucaceae, Fucus, F. serratus). (12 kg of fresh seaweeds). Sample collected were transported to the laboratory immediately and were gently rinsed with filtered water, then dried at $50^{\circ} \mathrm{C}$. These dried seaweed samples were shredded to small pieces by a wiring blender to recuperate about $2 \mathrm{~kg}$ of small dried seaweed $(250 \mu \mathrm{m})$.

\subsection{Extract preparation}

The dried seaweed samples were extracted with $5.6 \mathrm{~kg}$ of solvent ( $3.6 \mathrm{~kg}$ of ethanol $96 \%+2 \mathrm{~kg}$ of water $=61.7 \%$ ethanol) for $17 \mathrm{~h}$, settled for $1 \mathrm{~h}$ and than filtered to recuperate $3.7 \mathrm{~kg}$ of extract. This latter was evaporated (1 kg of extract recuperated), filtered and finally freezed and lyophilised.

\subsection{Determination of total polyphenol contents (TPC) in seaweed extracts}

To determine the TPC of these seaweed extracts we have used Folin-Glombitza method. According to this method, the extract is dissolved in water; Folin-Ciocalteu's phenol reagent is added after incubation for $30 \mathrm{~min}$ (Pharmacopoeia Europea). The absorbance is measured at $760 \mathrm{~nm}$. For calibration phloroglucinol is treated in the same way. First, $200 \mathrm{mg}$ of phloroglucinol is dissolved in $100 \mathrm{ml}$ of water (solution a). Further $5 \mathrm{ml}$ of the solution a is diluted up to $100 \mathrm{ml}$ with water (solution b). To $2 \mathrm{ml}$ of the solution b, $10 \mathrm{ml}$ of water, $1 \mathrm{ml}$ of Folin reagent and $12 \mathrm{ml}$ of a $\mathrm{Na}_{2} \mathrm{CO}_{3} 10$ $\mathrm{H}_{2} \mathrm{O}(29 \% \mathrm{~m} / \mathrm{V})$ were mixed (final volume $\left.25 \mathrm{ml}\right)$. The mixture is incubated for $30 \mathrm{~min}$ in the dark at room temperature. Thereafter, the absorbance is measured at $760 \mathrm{~nm} v$ s. the blank. The blank is prepared identically as described before; the only difference is that 
we will replace the phloroglucinol solution by water. After 30 min in the dark the blank solution has to remain colourless. For the calibration curve the following concentrations of phloroglucinol were used: $0,3,4,5$ and $6 \mathrm{ml}$ of the solution a were used and treated as described above.

For the determination of total phenolic contents (TPC) in solid extracts: $50 \mathrm{mg}$ of the dry extract was dissolved in $25 \mathrm{ml}$ of water (solution c). $10 \mathrm{ml}$ of the solution $\mathbf{c}$ is diluted with water up to $25 \mathrm{ml}$ (solution d). $2 \mathrm{ml}$ of the solution d was treated as described above. The absorbance values, at $760 \mathrm{~nm}$ of the sample solution, should be between 0.3 and 0.8 .

\subsection{DPPH stable free radical scavenging activity}

A solution of $3.10^{-4} \mathrm{M}$ of DPPH is prepared by dissolving $11.83 \mathrm{mg}$ of 2,2-diphenyl-1-picrylhydrazyl in $100 \mathrm{ml}$ of solvent (methanol/water $90 \% \mathrm{v} / \mathrm{v}$ ). The reference, i.e. $0 \%$ of inhibition, is prepared by adding $300 \mu$ of demineralised water to $3 \mathrm{ml}$ of DPPH solution. For each sample, various dilutions (dilutions from 2 to 4 ) were carried out starting from the solutions prepared for the measuring out of the phenolic compounds (50 mg of extract in $50 \mathrm{ml}$ of demineralised water). The purpose of these dilutions is to lay the inhibition percentage $\left(\mathrm{IC}_{50}\right.$ ) between $30 \%$ and $70 \%$. Once the mixture of the solution to measure out $(300 \mu \mathrm{l}$ of the extract $+3 \mathrm{ml}$ of DPPH solution) is mixed, we incubate all the solutions for $1 \mathrm{~h}$ in the dark at room temperature (Blois, 1958). Thereafter the absorbance is measured at $517 \mathrm{~nm}$ against the blank. The blank solution is prepared from demineralised water.

\section{Results and discussions}

\subsection{Spectroscopic study of seaweed extracts}

The Folin method is based on the reactivity between polyphenol extracts and the Folin-Ciocalteu reagent. This reactivity most be compared and normalised with a known product, if possible similar to the monomer structure of the main polymer of the extracts. Our polyphenols are polymers based on phloroglucinol units; this is why the calibration was carried out on phloroglucinol dehydrated monomer. Once the calibration is realised, the absorbance of samples can be normalised to a phloroglucinol equivalent (PGE) concentration. Each sample was the subject of three specimen tests and three measurements for each specimen were realised.

It is to be noted that, two series of tests were experienced on those extracts stoked in the ENSCR (Ecole Nationale Supérieure de Chimie de Rennes) laboratories and those stoked in the LEBHAM (Laboratoire d'Ecophysiologie et de Biotechnologie des Halophytes et Algues Marines de l'UBO) laboratories. Two independent laboratories, two equipments and two operators were involved in the statistical evaluation of the method. Thus, the fidelity of the method was examined intraday and interlaboratories. Thereafter, the results obtained from the tests of the three extracts of seaweed's are drawn in Table 1.

These values give us an idea of the polyphenol contents of the seaweed extracts. Thus, as shown in these results, the precision

\section{Table 1}

Mass percentage of the three seaweed extracts expressed in phloroglucinol equivalent $(\mathrm{PGE}) \pm$ express the interlaboratory relative standard variation.

\begin{tabular}{llll}
\hline & $\begin{array}{l}\text { Fucus } \\
\text { vesiculosus }\end{array}$ & $\begin{array}{l}\text { Ascophyllum } \\
\text { nodosum }\end{array}$ & $\begin{array}{l}\text { Fucus } \\
\text { serratus }\end{array}$ \\
\hline ENSCR specimens & $22.79 \pm 0.10$ & $21.54 \pm 0.22$ & $12.43 \pm 0.09$ \\
LEBHAM specimens & $22.63 \pm 0.12$ & $21.30 \pm 0.14$ & $12.29 \pm 0.10$ \\
Average & $22.71 \pm 0.08$ & $21.42 \pm 0.12$ & $12.36 \pm 0.07$ \\
\hline
\end{tabular}

of theses tests is relatively good. It should be noted that the reaction is sensitive to the variations of the multiple parameters as humidity, temperature and pressure. The experimental results indicated that the TPC of the ethanol/water extracts of Fucus Vesiculosus, Ascophyllum Nodosum and Fucus Serratus were 22.71, 21.42 and $12.36 \mathrm{~g}$ PGE/100 g extract, respectively.

\subsection{DPPH radical scavenging activity}

The antioxidant activity, so called antiradicalaire, is the capacity of a compound to be reacted preferentially with the radicals. The DPPH (2,2-diphenyl-1-picryl-hydrazyl) is a coloured radical (purple), the polyphenols play the role of "radical scavenger" (literally trapper of radicals which leads after reaction to its discoloration). The attenuation in absorbance, at a specified wavelength, is measured by a spectrometer, and then brought back to a percentage of inhibition using the formula below (Malllet, Cerrati, Ucciani, Gamisans, \& Gruber, 1994):

Inhibition percentage $=\left(\left(a b s_{0}-\mathrm{abs}_{x}\right) / \mathrm{abs}_{0}\right) \times 100$

with $\mathrm{abs}_{0}$ corresponding to the absorbance of a reference which does not contain polyphenols (which corresponds to $0 \%$ of inhibition) and $\mathrm{abs}_{x}$ the absorbance of the sample. Different concentrations of samples are tested so as to obtain a curve giving the inhibition percentage according to the concentration (linear between $40 \%$ and $60 \%$ ). Once the slope obtained, it is easy to obtain the concentration which gives $50 \%$ of inhibition $\left(\mathrm{IC}_{50}\right)$. Thus, five different concentrations were studied for each sample and each measurement was tested four times. Thereafter, we obtained the average inhibition percentage in function of the extract's concentration (Fig. 1).

A linear correlation was found for each seaweed extract in a given concentration range which is dependent on the reactivity of the substrate toward the DPPH solution. The key point in this study was to demonstrate a linear interval of $\mathrm{IC}_{50}$ allowing the determination of antioxidant capacity values of each extract.

These graphs enable us also to obtain the $\mathrm{IC}_{50}$ for each extract (Table 2).

Therefore we can only compare the samples between them: Fucus serratus is less reactive, according to the selected method, than Ascophyllum nodosum which is less reactive than Fucus vesiculosus. Indeed, the results once brought back into phloroglucinol equivalent (PGE), taking into consideration the results of the Table 1 "results of Folin-Glombitza method", we can observe that the tendency is inverse and we have different reactivity: Ascophyllum

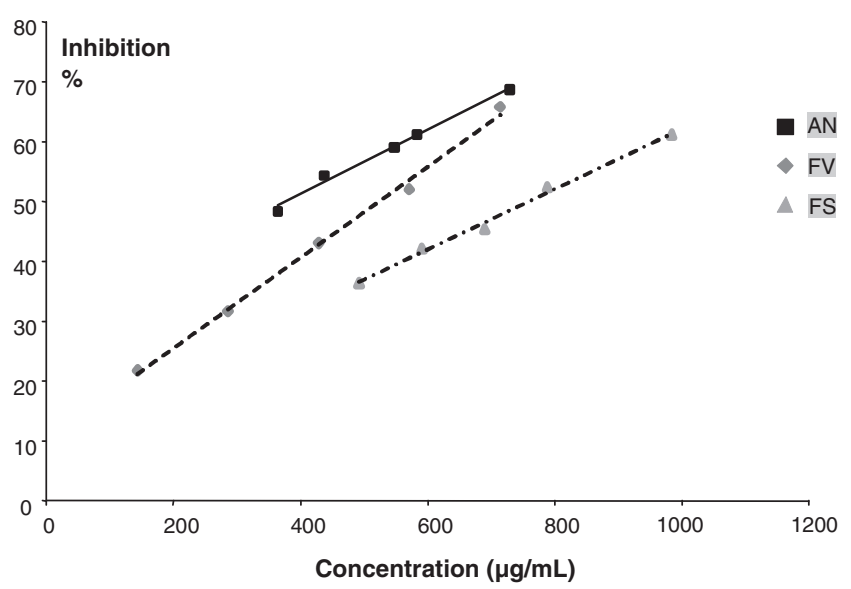

Fig. 1. Inhibition percentage in function of the mass concentration of the three seaweed's extracts: $\mathrm{FV}=$ Fucus vesiculosus, $\mathrm{AN}=$ Asophyllum nodosum and $\mathrm{FS}=$ Fucus serratus. 
Version définitive du manuscrit publiée dans / Final version of the manuscript published in :

Food Chemistry (2011), Vol. 126, p. 831-836, DOI: 10.1016/j.foodchem.2010.10.061

Journal homepage : www.elsevier.com/locate/foodchem

Table 2

Characteristic parameters for the regression equation for the seaweed's extracts antioxidants. $\mathrm{IC}_{50}$ for each seaweed extract expressed in $\mu \mathrm{g} / \mathrm{ml}$ of mass extracts and in $\mu \mathrm{g} / \mathrm{ml}$ of PGE.

\begin{tabular}{llll}
\hline & \% of PGE & $\begin{array}{l}\mathrm{IC}_{50} \mathrm{~g} / \mathrm{ml} \text { of extract } \\
\text { mass }\end{array}$ & $\begin{array}{l}\mathrm{IC}_{50} \mathrm{~g} / \mathrm{ml} \text { of } \\
\mathrm{PGE}\end{array}$ \\
\hline F. vesiculosus & $22.71 \pm 0.08$ & 521.93 & 118.54 \\
A. nodosum & $21.42 \pm 0.12$ & 376.74 & 80.70 \\
F. serratus & $12.36 \pm 0.07$ & 758.11 & 93.82 \\
\hline
\end{tabular}

nodosum is more reactive than Fucus serratus, and this later is more reactive than Fucus vesiculosus. Although Fucus serratus contains less phloroglucinol monomers than Fucus vesiculosus, but it seems that Fucus serratus polymers are better radical scavenger than Fucus vesiculosus. Fucus serratus can delocalise more efficiently radicals on their polymer cycles. In general, we can distinguish a very good scavenging capacity for these seaweed extracts which can be very useful for the industries as an excellent raw material reach in antioxidant.

\subsection{Voltammetric behaviour of seaweed and apple extracts}

The oxidation potentials of seaweed's extracts were obtained by cyclic voltammetry $(\mathrm{CV})$. The range of potential varies from 0 to $1.5 \mathrm{~V}$ vs. $\mathrm{Ag} / \mathrm{AgCl}$. The potentials of anodic oxidation of the polyphenols $\left(E_{\mathrm{a}}\right)$ were given preliminary from the anodic wave of the voltammogramme. The effect of various extracts was checked by the method of the proportioned additions and the successive addition of $100 \mu \mathrm{l}$ of initial solution of extract $(40 \mathrm{mg} / \mathrm{ml})$. It should be mentioned that all the studies were realised at $20^{\circ} \mathrm{C}$ in an aprotic media DMF. Also, in each work session the electrode was cleaned by polishing its surface. As it is well known, and as we have seen before, in the spectrophotometric protocol only one measurement is carried out (absorbance at specific wavelength). However, in the electrochemical protocol different oxidation potentials can be tested simultaneously. This fact, would allow carrying out a selective measurement of "total oxidations" from different polyphenol compounds. The polyphenols generally oxidise according to a mechanism with two electrons.

Thus, in this work we have tested the electrochemical oxidation of the three seaweed extracts compared with the oxidation potential of the phloroglucinol and then the oxidation of the apple extracts compared with the oxidation potential of epicatechin (Fig. 2).

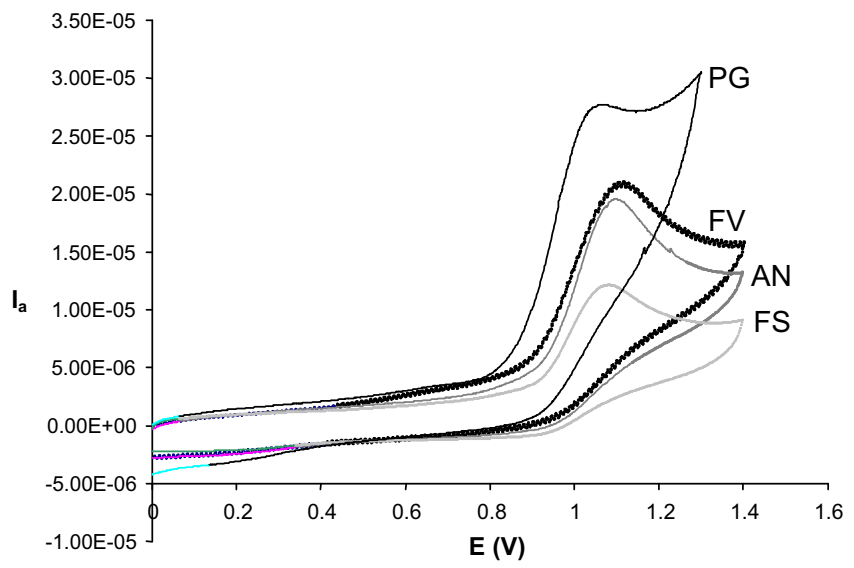

Fig. 2. Cyclic voltammetry of FV, AN and FS ( $800 \mathrm{mg} / \mathrm{l})$ and $\mathrm{PG}(2 \mathrm{mM})$ at a steady glassy carbon disk electrode in $\mathrm{DMF} / 0.1 \mathrm{M} \mathrm{Bu}_{4} \mathrm{NPF}_{6}$. Scan rate $0.1 \mathrm{Vs}^{-1}$.
The oxidation peaks of the three seaweed extracts are positioned at the same potential as the one for phloroglucinol $(1.1 \mathrm{~V}$ vs. $\mathrm{Ag} / \mathrm{AgCl}$ ) what confirms that all extracts are composed from the same monomer: the phloroglucinol. Additionally, the oxidation peak of apple extracts are located at $1.0 \mathrm{~V}$ and the second at $1.3 \mathrm{~V}$ $v s . \mathrm{Ag} / \mathrm{AgCl}$ respectively, which correspond exactly to the oxidation peaks of the epicatechin what confirms also the epicatechin base in these apple extracts. Using this type of analysis, cyclic voltammetry, let us test new type of polyphenol extracts to determine their global phenolic consistence. Thereafter, to complete this work we must study and have a list of anodic wave potentials for a number of monomers so we can be able to compare an unknown sample composition by a simple association of its anodic potential. That is why we decide to test a large number of polyphenols components to have an electrochemical index for each molecule, and as result we can build a data based on all polyphenols used in the industrial sectors.

Since the peak's height is proportional to the concentration of the electroactive compounds, a good linear correlation between the spectrometric study and the electrochemical study was obtained.

In this comparison we have tested the same weight of seaweed extracts and we have obtained an excellent correlation between spectroscopic methods and electrochemical methods. Therefore, using electrochemical techniques permit us to make sure that Fucus vesiculosus is richer than Ascophyllum nodosum in phloroglucinol equivalent, and this latter is richer than Fucus serratus.

\subsection{Voltammetric behaviour of a large number of polyphenols reagents}

A large number of polyphenols were tested by cyclic voltammetry method to determine their oxidation potentials. The initial solutions of polyphenols or substrate were prepared so that in the reaction medium $\left(\mathrm{DMF} / \mathrm{Bu}_{4} \mathrm{NPF}_{6} 0.1 \mathrm{M}\right)$ their concentrations vary from $1.10^{-4}$ to $5.10^{-3} \mathrm{M}$. Before each measurement the reaction medium was mixed and the working electrode was polished during $1 \mathrm{~min}$ using a polishing machine provided with a silicon carbide paper of grain 4000 (Struers, Ballerup, Denmark), then rinsed with distilled water.

The various polyphenol extracts and components were readily oxidised in the potential range from 0.5 to $1.3 \mathrm{~V} v$ s. $\mathrm{Ag} / \mathrm{AgCl}$, as shown in the cyclic voltammograms below. In each case the top

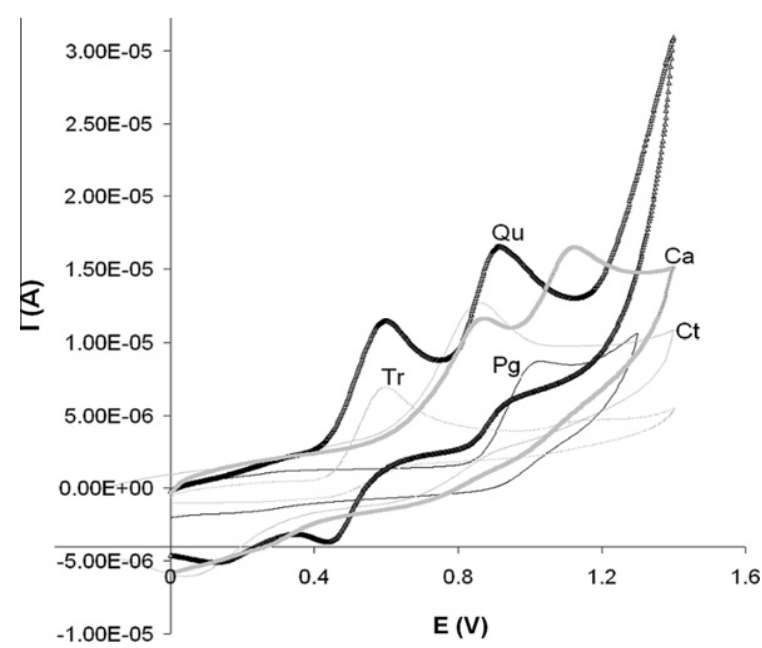

Fig. 3. Cyclic voltammetry of $1 \cdot 10^{-3} \mathrm{M}$ of Phlorogucinol (Pg), Trolox (Tr), Quercetin $(\mathrm{Qu})$, Catechin $(\mathrm{Ca})$ and Catechol $(\mathrm{Ct})$ at a steady glassy carbon disk electrode in $\mathrm{DMF} / 0.1 \mathrm{M} \mathrm{Bu}_{4} \mathrm{NPF}_{6}$. Scan rate $0.1 \mathrm{Vs}^{-1}$. 
Version définitive du manuscrit publiée dans / Final version of the manuscript published in :

Food Chemistry (2011), Vol. 126, p. 831-836, DOI: 10.1016/j.foodchem.2010.10.061

Journal homepage : www.elsevier.com/locate/foodchem

Table 3

Cyclic voltammetry characteristics, $E_{\mathrm{a}}(\mathrm{V}) v s$. $\mathrm{Ag} / \mathrm{AgCl}, I_{\mathrm{a}}(\mu \mathrm{A})$, of a number of phenolic compounds.

\begin{tabular}{|c|c|c|c|c|c|}
\hline Phenolic compounds & $E_{\mathrm{a} 1}(\mathrm{~V})$ & $E_{\mathrm{a} 2}(\mathrm{~V})$ & Phenolic components & $E_{\mathrm{a} 1}(\mathrm{~V})$ & $E_{\mathrm{a} 2}(\mathrm{~V})$ \\
\hline Sinapic acid & 0.85 & 1.14 & Phloroglucinol & 1.10 & \\
\hline Cafeic acid & 1.00 & - & Catechol & 0.96 & \\
\hline Chlorogenic acid & 1.09 & - & $(+)$-Catechin & 0.96 & 1.24 \\
\hline Ferulic acid & 1.23 & - & (-)-Epicatechine & 0.96 & 1.24 \\
\hline$p$-Coumaric acid & 1.28 & - & Phloridzin & 1.30 & \\
\hline Quercitin & 0.84 & 1.11 & Ascorbic acid & 1.02 & \\
\hline Rutine & 0.94 & 1.60 & Trolox & 0.81 & \\
\hline
\end{tabular}

scan represents the oxidation of the polyphenol compounds generating a positive (anodic) current, peaking at a particular electrode potential; the lower the potential of oxidation, the more powerful the phenolic compound is, as a reducing agent. On the reverse scan a negative (cathodic) peak is produced where the oxidised form of the phenolic compounds can be reduced back to its original form. For example, the oxidation of quercitin $(\mathrm{Qu})$ can be readily reversed at the carbon electrode, while Trolox (Tr) is irreversibly oxidised (Fig. 3).

A number of parameters can be extracted from the cyclic voltammetry curves to characterise the phenolic compounds as reducing agents, and these values are recorded in the Table 3 . During the positive scan, we obtain one or two anodic peak potentials $\left(E_{\mathrm{a} 1}\right.$ and $\left.E_{\mathrm{a} 2}\right)$.

The hydroxycinnamic acids (Sinapic, Cafeic, Chlorogenic, ferulic, coumaric) present only one irreversible wave of oxidation between 0.9 and $1.3 \mathrm{~V}$ except the sinapic acid which presents two waves of oxidation, a wave at $0.85 \mathrm{~V}$ and the other at $1.14 \mathrm{~V}$. As expected, more the number of phenolic substituents on the aromatic nucleus is important the more the potential of oxidation is low. The $p$ coumaric acid and the ferulic acid (monophenol) have a potential of oxidation higher than the caffeic acid and the chlorogenic acid (diphenol). These results are in agreement with the literature (Aaby, Hvattum, \& Skrede, 2004; Guo, Cao, Sofic, \& Prior, 1997; Peyrat-Maillard, Bonnely, \& Berset, 2000). The addition of a methoxy function on the aromatic nucleus of the hydroxycinnamic acids has a slight influence on the potential of oxidation. The $p$-coumaric acid oxidises at a potential of $1.28 \mathrm{~V}$ and the ferulic acid at a potential of $1.23 \mathrm{~V}$.

The monomeric flavonoïdes present two irreversible stages of oxidation except phlorizin which presents only one of them $(0.8-$ $1.2 \mathrm{~V}$ ). The first step of oxidation is located between 0.8 and $1 \mathrm{~V}$ and the second between 1.1 and $1.6 \mathrm{~V}$. Monomeric flavan-3-ols, catechol and (+)-catechin and (-)-epicatechin, have the same electrochemical behaviour, means the same oxidation peaks at 0.96 and 1.24 V (Blasco, González, \& Escarpa, 2004). The glycosilation of quercetin in position $3^{\prime}$ causes an increase in its oxidation potentials. The potentials of oxidation of quercetin are of 0.84 and $1.11 \mathrm{~V}$ compared with the rutin peaks which are located at 0.94 and $1.60 \mathrm{~V}$ (Kilmartin, Zou, \& Waterhouse, 2001). Phloridzin has the potential of the highest oxidation amongst the flavonoïdes tested at the time of this study. The first potential of oxidation can be allotted to the oxidation of the components of the core B. On the other hand, the attribution of the second potential of oxidation is more difficult. It could correspond to the oxidation of the substituents of cores A or C. The ascorbic acid has only one potential peak of oxidation at $1.02 \mathrm{~V}$, the trolox a peak at $0.81 \mathrm{~V}$ and the phloroglucinol has as well only one potential of oxidation at $1.10 \mathrm{~V}$.

\section{Conclusion}

The results of this screening experiment demonstrated that the different seaweed species from Brittany contained different levels of TPC and possess diverse antioxidant properties. The type of extracts has a great impact both on TPC and antioxidant seaweed's activity. Thus, based on spectrophotometric analysis, the TPC of the ethanol/water extracts of Fucus vesiculosus, Ascophyllum nodosum and Fucus serratus were 22.71, 21.42 and $12.36 \mathrm{~g}$ PGE/100 g extract, respectively. However, when realising the antioxidant tests $\left(\mathrm{IC}_{50}\right.$ $\mu \mathrm{g} / \mathrm{ml}$ of PGE) with the 2,2-diphenyl-1-picrylhydrazyl (DPPH) radical scavenging, we can deduce that the order of reactivity has changed and Ascophyllum nodosum became the most reactive than Fucus serratus and than Fucus vesiculosus.

In the second part of this work, we have used an electrochemical technique, cyclic voltammetry, to check the oxidation potential of these three extracts $(1.1 \mathrm{~V} v s$. $\mathrm{Ag} / \mathrm{AgCl})$ and thus, we have obtained a good correlation between spectroscopic methods and electrochemical methods for the three seaweed's extracts. Due to these results we have realised several cyclic voltammograms concerning a number of polyphenol monomers and we have studied their properties. In this paper, we have established that cyclic voltammetry can be effectively used to characterise the reducing ability and reversibility of antioxidant standards and the reducing contents of seaweeds and polyphenol compounds. Thus, the use of electrochemistry could be an attractive alternative to spectrophotometric protocols to determine "total phenolic contents" and antioxidant capacity. The proposed electrochemical protocol is easy, fast and showed a good precision and a high sample throughout. After all, we could say that this concept could be extended to other total determinations of electroactive compounds of foods.

\section{Acknowledgements}

The CEVA (Centre d'Etude et de Valorisation des Algues, Pleubian, France), for their seaweed's samples, the "Laboratoire de Chimie Analytique, Faculté de Pharmacie de l'Université de Rennes 1", the "Conseil Régional de Bretagne", the "Critt Santé Bretagne" and Diana Vegetal for their financial supports.

\section{References}

Aaby, K. Hvattum, E. \& Skrede, G. J. (2004). Analysis of flavonoids and other phenolic compounds using high-performance liquid chromatography with coulometric array detection: Relationship to antioxidant activity. Journal of Agricultural Food Chemistry, 52(15), 4595-4603.

Benzie, I. F., \& Strain, J. J. (1996). The ferric reducing ability of plasma (FRAP) as a measure of "antioxidant power": The frap assay. Analytical Biochemistry, 239(1), 70-76.

Blasco, A. J., González, M. C. \& Escarpa, A. (2004). Electrochemical approach for discriminating and measuring predominant flavonoids and phenolic acids using differential pulse voltammetry: Towards an electrochemical index of natural antioxidants. Analytica Chimica Acta, 511(1), 71-81.

Blois, M. S. (1958). Antioxidant determination by the use of a stable free radical. Nature, 181, 1199-1200.

Cao, G., Alessio, H. M., \& Culter, R. G. (1993). Oxygen-radical absorbance capacity assay for antioxidants. Free Radical Biology and Medicine, 14(3), 303-311.

Cao, G., Sofic, E., \& Prior, R. (1996). Antioxidant capacity of tea and common vegetables. Journal of Agricultural Food Chemistry, 44(11), 3426-3431.

Guo, C., Cao, G., Sofic, E., \& Prior, R. L. (1997). High-performance liquid chromatography coupled with coulometric array detection of electroactive components in fruits and vegetables: Relationship to oxygen radical absorbance capacity. Journal of Agricultural Food Chemistry, 45(5), 1787-1796. 
Version définitive du manuscrit publiée dans / Final version of the manuscript published in :

Food Chemistry (2011), Vol. 126, p. 831-836, DOI: 10.1016/j.foodchem.2010.10.061

Journal homepage : www.elsevier.com/locate/foodchem

Guo, C. J., Yang, J. J., Wei, J. Y., Li, Y. F., Xu, J., \& Jiang, Y. G. (2003). Antioxidant activities of peel, pulp and seed fractions of common fruits as determined by FRAP assay. Nutrition Research, 23(12), 1719-1726.

Halliwell, B. (1996). Antioxidants in human health and disease. Annual Review of Nutrition, 16, 33-50.

Halliwell, B. (1999). Food-derived antioxidants. Evaluating their importance in food and in vivo. Food Science and Agricultural Chemistry, 1, 67-109.

He, Y., \& Shahidi, F. (1997). Antioxidant activity of green tea and its catechins in a fish meat model system. Journal of Agricultural Food Chemistry, 45(11), 4262-4266.

Kilmartin, P. A., Zou, H., \& Waterhouse, A. L. (2001). A cyclic voltammetry method suitable for characterizing antioxidant properties of wine and wine phenolics. Journal of Agricultural Food Chemistry, 49(4), 1957-1965.

Kowaltowski, A. J., \& Vercesi, A. E. (1999). Mitochondrial damage induced by conditions of oxidative stress. Free Radical Biology and Medicine, 26(3-4), 463-471.

Malllet, J. F., Cerrati, C., Ucciani, E., Gamisans, J., \& Gruber, M. (1994). Antioxidant activity of plant leaves in relation to their alpha-tocopherol content. Food Chemistry, 49(1), 61-65.

Moore, S., Calder, K. A. C., Miller, N. J., \& Rice-Evans, C. (1994). Antioxidant activity of saliva and periodontal disease. Free Radical Research, 21(6), 417-425.

Peyrat-Maillard, M. N., Bonnely, S., \& Berset, C. (2000). Determination of the antioxidant activity of phenolic compounds by coulometric detection. Talanta, 51(4), 709-716.
Pharmacopoeia Europea 4.00, 2.8.14.

Pinzani, P., Petruzzi, E., Orlando, C., Gallai, R., Serio, M., \& Pazzagli, M. (1998). Serum antioxidant capacity in healthy and diabetic subjects as determined by enhanced chemiluminescence. Journal of Bioluminescence and Chemiluminescence, 13(5), 321-325.

Pratt, D. E. (1992). Natural antioxidants from plant material. Phenolic compounds in food and their effects on health II, ACS symposium series, 507, 54-71.

Prior, R. L., \& Cao, G. (1999). In vivo total antioxidant capacity: Comparison of different analytical methods. Free Radical Biology and Medicine, 27(11-12), 1173-1181.

Re, R., Pellegrini, N. P., Proteggente, A., Pannala, A., Yang, M., \& Rice-Evans, C. (1999). Antioxidant activity applying an improved ABTS radical cation decolorization assay. Free Radical Biology and Medicine, 26(9-10), 1231-1237.

Rice-Evans, C. A., \& Miller, N. J. (1998). Flavonoids in health and disease. In C. A Rice-Evans \& L. Packer (Eds.), Marcel Dekker (pp. 199-219). New York.

Roginsky, V., \& Lissi, E. A. (2005). Review of methods to determine chain-breaking antioxidant activity in food. Food Chemistry, 92(2), 235-254.

Simic, M. G., \& Bergtold, D. S. (1991). Dietary modulation of DNA damage in human. Mutation Research/Fundamental and Molecular Mechanisms of Mutagenesis, 250(1-2), 17-24.

Van Den Berg, R., Haenen, G. R. M. M., Van Den Berg, H., \& Bast, A. (1999). Applicability of an improved Trolox equivalent antioxidant capacity (TEAC) assay for evaluation of antioxidant capacity measurements of mixtures. Food Chemistry, 66(4), 511-517. 